\title{
La terminología del vino y la viña jerezana en inglés. Un caso concreto
}

\author{
Sherry Wine-making and Vineyard Terminology in English. A Case Study \\ Paloma López Zurita \\ Universidad de Cádiz, España. \\ Correo electrónico: paloma.lopez@uca.es
}

\begin{abstract}
Este artículo presenta el estudio de la terminología viti-vinícola del marco del jerez (España) a través de un caso concreto: la obra Gatherings from Spain, de gran impacto en el XIX. El objetivo es determinar cuáles son los mecanismos lingüísticos de traslación interidiomática utilizados para transferir del español al inglés términos y expresiones antropológicamente relacionados con las tradiciones vinateras. Los resultados evidencian cómo el carácter de los elementos iniciales determina el tipo de mecanismo utilizado, dependiendo de si se trata de términos científicos generales y comunes a la producción de vino o de términos relacionados con las costumbres culturales de los distintos enclaves geográficos. Estos últimos configuran una terminología vinícola local determinada, llegando en muchos casos incluso a la incorporación de este léxico a la lengua de llegada.
\end{abstract}

Palabras clave: terminología, traducción, vitivinicultura, sherry, Jerez

This paper presents the study of the sherry wine-making terminology (Spain) through a case study: the book Gatherings from Spain, of great impact in the 19th century. Our main purpose is to identify the linguistic mechanisms used to transfer from Spanish into English those elements so closely related to the anthropological traditional wine-making method in the Jerez area. Results show how the characteristics of the initial elements determine the type of mechanism used, depending on whether they refer to general scientific terms or to those related to the cultural customs of different geographic locations. These latter make up a local specific wine terminology, whose vocabulary, in many cases, has been incorporated into the target language.

Key words: terminology, translation, viticulture, sherry, Jerez 


\section{INTRODUCCIÓN}

Durante su periplo por España a mediados del siglo XIX Richard Ford, famoso viajero británico, visitó la ciudad de Jerez y su entorno. Procedente de un país aficionado desde antiguo al vino producido en esta localidad del Sur de España, sherry, Ford se detiene en esta zona para comentar su producción y tipología. En este proceso, se producen interferencias entre su lengua materna, inglés, y la lengua del país en el que se desarrolla la actividad vinícola, español. Por este motivo, se crea un texto cargado de términos, expresiones, giros, etc. que, o bien se incorporan directamente como préstamos del español o, aún en inglés, denotan claramente la procedencia de este idioma a través de calcos léxicos y de traducciones tan directas que a menudo no presentan sentido alguno para el angloparlante que no conozca este idioma. Asimismo, esta continua interacción lengua-realidad es muestra de la imposibilidad de separar el uso y dominio óptimo de una lengua del conocimiento de la cultura y del medio en el que esta se desarrolla: Según Malinowski (Cit. en Ullman 1983: 50) "The study of any language, spoken by a people who live under conditions different from our own and possess a different culture, must be carried out in conjunction with the study of their culture and of their environment”. A veces, la mala interpretación o inadecuación contextual de algunas expresiones se debe precisamente a la deficiente comprensión de los conceptos y viceversa. Esta distinta organización cultural de la realidad plantea infinidad de problemas léxicos y semánticos para su traslación de una lengua a otra (Trujillo 1997), siendo necesario utilizar una serie de mecanismos lingüísticos para ello. Esta dificultad se evidencia aún más en el mundo del vino, ya que "Al hablar de un vino en concreto no solo se hace referencia a sus características organolépticas, su color, su aroma, su sabor, etc., sino que también se hace alusión a todos aquellos rasgos que determinan su identidad, rasgos que van inexorablemente unidos a la tradición, la cultura y la idiosincrasia del lugar de origen” (Feu, de la Cuadra y Sánchez 2003: 53).

Por un lado, la producción, elaboración y consumo de vinos es una práctica tan extendida que comparte en el ámbito internacional una serie de términos vinícolas generales que sí configuran este campo como una terminología científica tradicional. Esto se debe principalmente a la inclusión de elementos pertenecientes a otras ciencias, como la Biología, la Química o la Enología, que suelen mantener en mayor medida la univocidad que a priori se le supone a una terminología e incluso léxico ordinario que en ese ámbito determinado adquiere el carácter de término: "Las unidades terminológicas son unidades del léxico de cada una de las lenguas asociadas a un valor especializado (es decir, un sentido preciso dependiente de dominio) que se activa por las condiciones pragmáticas de la situación comunicativa en la que se usan (marcos situacionales)” (Cabré 2007: 71-84).

Por otro lado, existe un tipo de terminología autóctona en cada zona productora de vino, cuya especificidad cultural plantea infinidad de problemas de traslación a una segunda lengua, ya que recoge términos y expresiones peculiares de un área geográfica, variaciones diatópicas sin equivalencia en otros contextos: "La variación en el lenguaje de la vid y el vino no queda solo en la perspectiva diacrónica o en la existencia de un doble registro (culto/popular), sino que se manifiesta también en la muy rica variación diatópica de su registro popular. Ya anotaba F. Carbonell en 1820 que cada viñedo tenía su idioma y su método” (Ibáñez Rodríguez 2007a: 86). 


\section{OBjetivos}

En el presente artículo el objetivo básico es el análisis de los términos de la viña y el vino (con especial énfasis en los jerezanos) que aparecen en la obra Gatherings from Spain en los que se ha producido algún tipo de interferencia entre la lengua del autor (inglés) y la lengua en la que se genera la realidad a plasmar (español). Nos situamos, por tanto, en un ámbito interidiomático en el que ambas lenguas se encuentran en continuo contacto en la mente del autor. Para ello nos serviremos de un amplio corpus de palabras, términos, expresiones fraseológicas, etc. que configura el campo asociativo en cuestión, recopilado a través de un minucioso análisis de la obra. En todo este recorrido cognoscitivo, nuestro principal objetivo ha de ser, en primer lugar identificar cuál es el elemento inicial en español que va a provocar la actuación de los mecanismos léxicos y semánticos de traslación a la lengua del autor; en segundo lugar, identificar cuáles son y de qué manera actúan esos mecanismos, para, finalmente, concluir en el elemento final en inglés resultante tras esa actuación, así como en su grado de fijación en la lengua de llegada.

La identificación del elemento inicial es obvia en aquellos casos en los que aparece junto al elemento final, recurso muy utilizado por Richard Ford, como se ejemplifica en la siguiente cita donde el elemento inicial es arrope y el final la perífrasis explicativa a sort of syrup: "The new wines, after the fermentation is past, are commonly enriched with an arrope, or sort of syrup [...]” (Ford 1846: 176)1. Sin embargo, también encontramos un gran número de expresiones en las que se elude ese elemento inicial, apareciendo tan solo el resultante final de la aplicación del mecanismo lingüístico. Estos casos son más difíciles de identificar. Como ejemplo, citaremos algunos de los numerosos casos encontrados:

- El uso de la perífrasis [must] boiled down to the fifth of its bulk por la expresión fraseológica especializada 'Arrope al quinto', que no aparece como tal en el texto: "The must, or new grape juice, before fermentation has commenced, is boiled slowly down to fifth of its bulk" (173).

- El uso de las perífrasis to doctor up worse sherry, [to add] a little fine old wine and brandy, o [to] correct young Sherry wines, which are running over sweet para referirse al término jerezano ‘cabeceo, -ar', que, de nuevo no aparece, probablemente por desconocimiento del término por parte del autor: "The fiery and acrid brandy [...] is sent to the Bay of Cadiz to the tune of I000 butts a year to doctor up worse sherry" (161); "[...] after that they are pressed and a little fine old wine and brandy is added" (165); "This amontillado [...] is used in correcting young Sherry wines, which are running over sweet” (169).

Todas estas interferencias conllevan un tipo de relaciones de designación, connotación y sentido pragmático a veces difícil de establecer, dado que la obra data del siglo XIX y que los únicos contextos fehacientes a los que podemos remitirnos son bien el propiamente lingüístico que el texto nos aporta, bien las obras que, acudiendo a autores anglófonos, aluden a estos términos a través de estudios sobre el jerez desde el punto de vista económico o comercial (Montañés 2000), histórico

Dado el elevado número de ejemplos utilizados en este artículo de la obra Gatherings from Spain (Ford 1846), en adelante solo se incluirá el número de página, quedando claro al omitir estos datos que nos referimos a esta obra y no a otra. 
(Jeffs 1994), etc. En muchos casos nuestro conocimiento, tanto del habla como de la realidad jerezana, hace posible la correcta interpretación de las expresiones y hechos aludidos. En otros casos, bien por la lejanía en el tiempo, el cambio de las costumbres o por la omisión por parte del autor de alguno de los elementos que toman parte en la interferencia entre ambas lenguas, asignar el sentido adecuado en cada caso requiere un proceso menos espontáneo e intuitivo. Por todo ello se deduce que, al estar dos lenguas en continuo contacto, el proceso cognoscitivo que se está produciendo en la mente de Richard Ford, salvo cuando sus comentarios no intentan reflejar la realidad española, es un acto continuo de traducción, casi siempre literal, no solo en contenido, sino también en estructura. Así, el resultado suele ser un texto difícil de comprender para un lector angloparlante. Como sucede en otros casos "una traducción literal preservaría superficialmente el original, pero le sería incomprensible a un lector de inglés" (Hatim y Mason 1995: 54). De manera habitual, y quizás por ser consciente de este problema, Richard Ford, además de insertar la llamada 'traducción literal', intenta clarificar el sentido de muchas expresiones a través de la inclusión de diferentes mecanismos lingüísticos que, en consecuencia, enmarcan al texto en un contexto aclaratorio y que analizaremos a continuación.

\section{Marco teórico. Antecedentes}

\subsection{La terminología viti-vinícola}

En las últimas décadas el estudio de la terminología del vino y la viña ha empezado a considerarse bajo el enfoque de la traducción especializada (Ibáñez Rodríguez 2007a, 2007b; Wislocka 2014), de la terminología aplicada a las lenguas para fines específicos (Bajo Santiago 2001; Ibáñez Rodríguez 2008, 2010a, 2010b), o desde una perspectiva intercultural (Wislocka 2012). Asimismo, se ha comenzado a analizar las variables diatópicas de muchas zonas vinícolas españolas, como La Rioja (Martínez Ezquerro 2007), Badajoz (Barros García 2008), Soria (Carracedo 2010), etc.

En cuanto al vino del marco de Jerez, si exceptuamos los diferentes glosarios que la mayoría de sus principales bodegas incluyen en sus webs, no abundan análisis académicos más detallados sobre su terminología específica. Entre los existentes, Smith y Casas (1982) nos aportan un análisis desde el punto de vista de los cambios semánticos, Paredes (2010) realiza un estudio de los términos utilizados en la cata de los vinos del marco del jerez y Noya (1993) lleva a cabo un minucioso análisis para establecer los mecanismos lingüísticos de traslación interidiomática más recurrentes por parte de escritores de habla inglesa en el ámbito de la terminología vinícola jerezana.

\subsection{Mecanismos lingüísticos de traslación interidiomática: plano léxico}

Bajo este epígrafe se agrupan aquellos mecanismos más utilizados en el plano léxico, cuyo objetivo original es completar una casilla léxica vacía en una lengua determinada a través de palabras, expresiones o términos procedentes de otra lengua, bien histórica (proceso interidiomático), bien funcional (proceso intraidiomático). Los más habituales en el campo asociativo de la viña y el vino en Gatherings from Spain son los siguientes: 
a) Préstamo: Este mecanismo lingüístico es sin duda el de mayor uso en el marco del contacto entre lenguas y el que ha supuesto una mayor profusión en su repertorio terminológico. En el ámbito lexicográfico, algunos autores se refieren a él como préstamo (Lázaro Carreter 1990; Lewandowski 1992). Otros (Dubois et al. 1992; Richards et al. 1993; Gómez Capuz 1998; Seco et al. 1999, etc.) prefieren utilizar expresiones diferentes, como el genérico 'trasplante’, o 'préstamo extranjero', así como ‘adopción lingüística’ o ‘aportación lingüística’ (Castro, en Lázaro Carreter 1990: 28). Richards utiliza el término inglés ‘borrowing’ para aglutinar de manera amplia todos los significados anteriores, añadiendo una serie de matices: "A word or phrase which has been taken from one language and used in another language [...] When a borrowing is a single word, it is called a loan word" (1993: 40). Por su parte, Dubois y otros consideran que se da un préstamo lingüístico cuando un habla adopta de otra un vocablo o estructura lingüística del que carecía, cuyo proceso de incorporación acaba en la integración en mayor o menor grado de esa unidad o rasgo en el habla de llegada(1992: 496-497). Algunos autores, como Payrató (1984) y Gómez Capuz (1998; 2000), tras estudiar las deficiencias terminológicas tradicionales en cuanto al término préstamo y considerar la polisemia que generan, presentan el término 'interferencia' como alternativo, con el siguiente significado:

La noción genérica de los fenómenos de contacto interlingüístico, creado expresamente para ser aplicado a situaciones de bilingüismo en las que surgían hechos de préstamo, que, efectivamente, afectaban a todos los niveles lingüísticos (y no sólo el léxico), implicaban con frecuencia la sustitución de un modelo extranjero (por medio de calcos de todo tipo) y, en suma, producían una verdadera reorganización de los patrones y estructuras de la lengua receptora (Gómez Capuz 1998: 101-102).

a.1. Por préstamo incorporado entendemos la adopción por parte de una lengua (aquí, inglés) de una palabra, término o expresión de procedencia extranjera (aquí, español), y cuya incorporación a la lengua de llegada ha podido ser constatada por su aparición en un diccionario de esa lengua ${ }^{2}$.

a.2. Por préstamo esporádico entendemos aquellos que, aunque en muchos casos sean de uso recurrente por el autor, su uso se debe a una situación concreta y no se encuentran incorporados al sistema de la lengua de llegada, por lo que no han podido ser constatados en ningún diccionario. Su grado de fijación a la lengua meta es escaso o nulo. En el apartado de préstamos esporádicos incluimos los denominados 'extranjerismos', con una acepción muy concreta, refiriéndonos a aquellos elementos prestados que proceden de una lengua distinta al español, para distinguirlos de los anteriores. Si bien estos elementos no se engloban dentro de los objetivos determinados en este trabajo, ya que este se restringe a las interferencias español/inglés, inevitablemente han de ser incluidos en él, pues forman parte de los mecanismos lingüísticos de traslación interidiomática mencionados, y suelen aparecer en unión a otros mecanismos de distinta naturaleza, mayoritariamente las expresiones perifrásticas. Es decir, en su afán clarificador, R. Ford no solo se ciñe a estas dos lenguas principales en su obra, sino que también recurre a través de otros idiomas a

Los principales diccionarios utilizados han sido The Compact Oxford English Dictionary y The Oxford Dictionary of English Etymology. 
la explicación de los elementos cuyo sentido no queda claro, normalmente el árabe (en busca de la etimología de las palabras españolas, no siempre acertada), el francés $\mathrm{y}$, en menor medida, el italiano, aunque también aparecen algunos casos de hebreo.

El motivo de esta distinción es puramente metodológico, con el objetivo de separar el conjunto global del campo asociativo, que se basa en una continua interacción entre el español y el inglés, de aquellas aportaciones más ocasionales, que, aun respondiendo a un fenómeno de la misma naturaleza, han de ser consideradas en un apartado distinto. Es decir, lo que aquí llamamos ‘extranjerismo’ podría denominarse asimismo préstamo procedente de una lengua distinta al español (y habitualmente esporádico). En ambos casos estamos situados en el límite de lo que generalmente se establece como préstamo. En este sentido coincidimos con J. Gómez Capuz en que un extranjerismo es la palabra que el hablante de la lengua receptora percibe como extraña, ya sea por su aspecto formal o por su uso restringido. Este autor emplea el término 'extranjerismo ocasional fuera del sistema', para referirse al mismo concepto que aquí hemos denominado 'préstamo esporádico’, pero reconoce que la frontera entre el préstamo y el extranjerismo en estos casos no queda clara (Gómez Capuz 1998).

a.3. Xenismo: El empleo de unos criterios culturales y etnológicos a la hora de catalogar un extranjerismo ha dado como fruto la creación y el uso del término 'xenismo'. Guilbert (1975) incluye bajo esta denominación todos los términos que hacen referencia a un significado específico de una lengua extranjera y su país correspondiente. No lo considera un tipo de préstamo, sino un mecanismo de cita con marcas metalingüísticas propias. Gómez Capuz (1998) considera el término ambiguo y sugiere otros términos alternativos. Para su acepción etnológica, sugiere 'exotismo', para su acepción lingüística, recurre a la terminología usada en otros idiomas como los ‘casuals', ‘occasionalismes', ‘citations’ o ‘mots étrangers’ o ‘palabra-cita' (Deroy 1980; Gusmani 1981; Alvar Ezquerra 1993; Mighetto 1993). Cabré utiliza el término xenismo con la siguiente acepción:

Hay que considerar los “xenismos” como un caso distinto a los préstamos, ya que son denominaciones de otras lenguas —no términos prestados— que designan conceptos culturalmente idiosincrásicos de la lengua a la que pertenecen: samurai, condottiero, perestroika. Si los "xenismos", al final de un proceso, llegan a designar un concepto propio también de la lengua de llegada (circunstancia que ocurre frecuentemente) pasan a considerarse préstamos. (Cabré 1993: 184)

Tras estas consideraciones a favor y en contra de su uso, coincidimos con la acepción de Cabré y consideramos el xenismo un caso de préstamo incorporado (pues se puede constatar por su aparición en diccionarios de lengua) en el que no solo el concepto original en sí es inexistente en la lengua de llegada, sino que, una vez incorporado a este sistema, no ha sido utilizado con otro sentido aplicable a una ampliación o cambio de significado. Su función es la de completar el vacío léxico creado en esa lengua para denominar una realidad también inexistente, al igual que el préstamo incorporado, pero la inexistencia de esa realidad lo configura como un término foráneo no aplicable a ningún concepto en la lengua meta. Los xenismos vitivinícolas encontrados son muy numerosos, entre ellos, como ejemplo: bodega (en su concepto jerezano), Xerez, manzanilla, etc.

b) Calco y equivalente: Como hemos visto, muchos autores incluyen el término ‘calco' en la definición de 'préstamo', considerándolo una parte o especialización del 
segundo. De nuevo, las definiciones de estos términos son abundantes (Lewandowski 1992; Dubois et al. 1992; Richards 1993, entre otros), pero volvemos a compartir la aportación de Cabré en este sentido: “La diferencia entre un préstamo y un calco reside en que un préstamo conserva inicialmente su forma originaria, y por lo tanto es a menudo identificable: un calco es la traducción literal de una palabra de otra lengua, por lo que parece una palabra genuina” (Cabré 1993: 191). Al parecer "una palabra genuina' el calco es en muchos casos difícil de identificar si no se conoce bien el origen de la palabra. Como ejemplo de esta dificultad, el corpus analizado incluye, entre otros, toothwater, como calco de 'aguardiente', en una errónea interpretación del término español (el error de Ford ha sido interpretar este compuesto como 'aguaal-diente’ en lugar de 'agua-ardiente’ de aquí el sorprendente término resultante). En este orden de ideas, no consideramos calcos, sino equivalentes, aquellas palabras traducidas directamente cuyo significado, sentido y uso sí se equipara al de la lengua de llegada en ese contexto determinado (Zuluaga 2001). Es el caso del término generalizante butt como 'bota', usado ya por los viajeros desde el siglos anteriores: "[...] and butts of the other (Sherry), which are sold neat as imported” (158).

c) Perífrasis: En la mayoría de los casos en que no existe en su lengua materna un elemento equivalente al que pretende utilizar en español, o su intención es aclarar su posible sentido, Ford acude al recurso de utilizar un giro o rodeo que lo explique o defina. Generalmente, este mecanismo léxico no aparece solo, sino que el autor lo emplea junto a otros, como se observa en la siguiente cita, de nuevo sobre la palabra 'bota', donde, además del propio préstamo esporádico se añaden varias perífrasis para delimitar su significado: "This Bota, whence the term Butt of sherry, bouteille, and bottle is derived, is the most ancient Oriental leathern bottle alluded to in Job xxxii. 19 [...] the shape is like that of a larger pear or shot-pouch, and it contains from two to five quarts. The narrow neck is mounted with a turned wooden cup, from which the contents are drunk” (110).

\subsection{Mecanismos lingüísticos de traslación interidiomática: plano semántico}

Los mecanismos lingüísticos que actúan en el plano semántico que aparecen más asiduamente en el campo asociativo analizado son la metonimia y sinécdoque, la metáfora y la elipsis. De acuerdo con Lázaro Carreter (1990) la metonimia es un tropo que responde a la fórmula lógica pars pro parte. Se produce cuando nombramos una cosa con el nombre de otra con la que puede mantener una de las siguientes relaciones: causa a efecto; continente a contenido; lugar de procedencia a cosa que de allí procede; materia a objeto; signo a cosa significada; abstracto a concreto, genérico a específico, etc. Como ejemplos: "Sherry indeed is not less popular among us than Murillo" (158), donde 'Sherry' aparece por la ciudad de Jerez; "but it was so called from the wine having been originally only made at Paxarete, a small spot near Xerez" (165), en el que el vino ha recibido el nombre del lugar en el que se produce Pajarete- (lugar de procedencia a cosa que de allí procede y viceversa).

Según este mismo autor, la sinécdoque es un tropo que responde al esquema lógico pars pro toto o totum pro parte. Se produce cuando nombramos una cosa con el nombre de otra con la que puede mantener una de las siguientes relaciones: género a especie y viceversa; parte a todo y viceversa; singular a plural y viceversa, etc. Otros autores acuden a la metáfora para definir el proceso metonímico (Lewansdoski 
1992), pero su distinción entre metonimia y metáfora no está tan clara para otros lingüistas, que incluso llegan a definir la sinécdoque como un tipo de metáfora. Así, Moliner considera la sinécdoque como una "metáfora que consiste en designar una cosa con el nombre de otra que no es más que una parte de ella [...] o con el de la materia de que está hecha [...] o con el de algo que lleva o usa" (Moliner 1992: 1172).

Por otra parte, para esta autora, la metonimia es una "figura retórica que consiste en tomar el efecto por la causa, el instrumento por el agente, el signo por la cosa, o viceversa" (Moliner 1992: 407). Estas definiciones siguen algo difusas, aunque parece generalmente aceptado que en la metáfora existe una relación de similitud entre el término real y el evocado, mientras que en la metonimia se establece una relación de contigüidad de sus significados.

En este orden de ideas, Quilis (1996: 77-78) aporta una definición bastante general de la metonimia, "la transferencia del nombre por contigüidad de los significados". Siguiendo a este autor, esta contigüidad puede ser

- Espacial; ejemplos en la obra analizada: "as among the modern ones is still done with Malaga or Vino de Cypro” (177), donde 'Málaga' aparece por el vino que allí se produce;

-Traslaciones del nombre de lugar propiamente dicho a la cosa, patente también en el anterior ejemplo;

-Traslación del nombre del continente al contenido: "a good rasher of bacon calls loudly for a corresponding long and strong pull at the "bota", a torresno de tocino, buen golpe de vino” (112), donde ‘bota’, como receptáculo de cuero utilizado en toda la geografía española, se utiliza con el sentido del vino que porta;

-Traslación de la cosa localizada al lugar: "The men employed in the sherry wine vaults [...] seldom touch it” (178) en donde 'sherry wine vaults' toma el valor de la bodega jerezana al completo;

-Traslación del nombre del contenido al continente: por ejemplo, se traslada la cualidad de envejecimiento del vino a las botas que lo contienen: "All the principal bodegas have certain huge and time-honoured casks”. (173);

-Temporal: En la cita que aparece a continuación se observa cómo la hora en que tiene lugar la comida ha pasado a denominar a ésta: "the next day lunch, las once, the eleven o'clock meal, as the Spaniards translate meridie, twelve or midday” (130);

- Causal. En el corpus analizado no aparece ningún caso de este tipo. Según Quilis (1996), la sinécdoque es un tipo de metonimia que toma la parte por el todo, relación que queda clara en el siguiente ejemplo: "these vins du pays, which are brought fresh to him from the skins or amphora jars” (160), donde la piel (skin) de la que está hecha la bota pasa a denominar a esta.

Tras todas las definiciones y clasificaciones anteriores, podríamos concluir que en la actualidad está admitido por la gran mayoría de los lingüistas el considerar a la sinécdoque como un tipo de metonimia, la que toma la parte por el todo y viceversa.

\section{Metodología}

A través de la lectura detenida de Gatherings from Spain, se han identificado, cuantificado y clasificado todos los casos de interferencias ${ }^{3}$ producidas entre las

Según la acepción de Gómez Capuz (1998) mencionada en el apartado anterior. 
dos lenguas en contacto, inglés y español, al intentar trasladar a su idioma nativo el sentido de unos elementos iniciales viti-vinícolas que llegan al autor a través de una segunda lengua que no domina totalmente. En esta clasificación, basada en las ya mencionadas sobre los vinos de jerez de Smith y Casas (1982) y Noya (1993), se han delimitado los siguientes planos: plano léxico. Se determina el carácter de los elementos iniciales que presentan dificultades de traducción al escritor y cuáles son los mecanismos léxicos más utilizados para solventarlas; plano semántico: Se establece qué mecanismos semánticos son más habituales y cuáles son las relaciones semánticas que suelen ir implícitas en todo este proceso de traslación de sentidos. Los datos obtenidos fueron clasificados e interpretados de manera conjunta, pues muestran una clara interdependencia.

En el plano léxico, bajo el epígrafe 'carácter del elemento inicial', se ha incluido el léxico común (palabras simples, inventadas o compuestos lexicalizados), el léxico especializado (términos simples y compuestos), las unidades fraseológicas (expresiones fraseológicas generales, especializadas y refranes), las traslaciones literales del discurso hablado y, finalmente, los nombres propios. Entre los mecanismos lingüísticos utilizados en cada caso, se incluye casos de préstamos (incorporados al sistema, de uso esporádico por el autor o xenismos); cultismos; calcos y equivalentes; perífrasis, simples o explicativas.

En el plano semántico distinguimos como mecanismos más utilizados la metonimia y sinécdoque, la metáfora y la elipsis. Finalmente, determinamos la naturaleza de las relaciones semánticas implícitas, siendo las más habituales las de generalización, es decir, de ampliación o extensión del significado original en el que el autor opta por un hiperónimo que engloba al elemento a traducir; las de especialización, es decir, de reducción o restricción del significado original, en el que los hipónimos cumplen esta función, o ninguno de los casos anteriores, donde encontramos cohipónimos que, salvando siempre las diferencias culturales y sin entrar en asumir si la sinonimia entre idiomas puede ser total o no, podrían considerarse sinónimos en ambas lenguas. De esta manera, el esquema resultante del análisis de la terminología de la viña y el vino en Gatherings from Spain es el siguiente:

\section{PLANO LÉXICO}

\section{A. Carácter del Elemento Inicial}

\section{A.1. Léxico común}

A.2. Léxico especializado

A.3. Unidades Fraseológicas

A. 4. Discurso Hablado

A.5. Nombres propios
A.1.1. Palabras

A.1.2. Palabras inventadas

A.1.3. Compuestos

A.2.1. Términos simples

A.2.2. Términos compuestos

A.3.1. Expresiones fraseológicas generales

A.3.2. Expresiones fraseológicas especializadas

A.3.3. Refranes 


\section{B. Mecanismos Léxicos}
B.1. Préstamo
B.1.1. Incorporado
B.1.2. Esporádico
B.1.3. Xenismo

B.2. Calco

B.3. Equivalente

B.4. Cultismo

B.5. Perífrasis

\section{B.5.1. Simple}

B.5.2. Explicativa

\section{PLANO SEMÁNTICO}

\section{A. Mecanismos semánticos}

A.1. Metonimia y Sinécdoque

A.2. Metáfora

A.3. Elipsis

B. Relaciones semánticas

B.1. Especialización (Hiponimia)

B.2. Generalización (Hiperonimia)

Las características del texto nos llevaron a establecer el siguiente proceso de recogida de datos: 1 . la expresión formal del elemento inicial que puede aparecer o no en el texto fuente y que ha sufrido la actuación de algún mecanismo lingüístico; 2. el elemento o elementos finales en los que se ha transformado tras sufrir la actuación de tales mecanismos; 3. el carácter del elemento inicial; 4. los mecanismos lingüísticos que afectan el caso determinado, léxicos y semánticos; 5. la relación semántica establecida y, finalmente; 6 . la cita en la que se engloba, para dotarlo de un contexto aclaratorio, necesario en la mayoría de los casos. A modo de ejemplo, se inserta una de las entradas analizadas:

1 Elemento inicial: Agraz

2 Elemento/s final/es:

a) agraz

b) the Moorish Hacaraz

c) delicious and refreshing drink

d) It is made of unpounded unripe grapes, clarified with sugar, and water

3 Carácter del elemento inicial: Término

$4 \mathrm{Mecanismo/s} \mathrm{lingüístico/s:}$

Préstamo esporádico + b) perífrasis explicativa/extranjerismo (árabe) + c) perífrasis explicativa + d) perífrasis explicativa.

5 Relación Semántica: Proceso de generalización.

6 Cita:

[...] the rich refrigerate themselves with agraz. This, the Moorish Hacaraz, is the most delicious and refreshing drink ever devised by thirsty mortal. [...] It is made of unpounded unripe grapes, clarified with sugar, and water. (157) 


\section{Resultados}

\subsection{Carácter del elemento inicial}

Analizar el campo asociativo del vino y la viña nos permite mostrar su carácter terminológico. Se trata de elementos terminológicos de carácter general, aplicables internacionalmente y, por ende, con univocidad y menor dificultad para ser trasladados de lengua a lengua, como sucede con las terminologías más científicas. Asimismo, se trata de términos correspondientes a ámbitos locales concretos, por lo que no existen esas equivalencias totales en la lengua de llegada. Así, esta terminología varía en gran medida cuando la referencia es un vino elaborado en una comarca o en otra. El análisis pormenorizado del corpus dio como resultado 107 elementos iniciales correspondientes al campo asociativo en cuestión. El hecho de tratarse de una terminología se demuestra por la notable aparición de léxico especializado, es decir, términos, simples o compuestos, y expresiones fraseológicas especializadas, que suponen un $87 \%$ del total. El resto de los elementos existentes son claramente minoritarios. El léxico común general tan solo alcanza un $8 \%$, las expresiones fraseológicas y refranes un $4 \%$ y los nombres propios un 1\%, tal y como se muestra en el siguiente gráfico.

Gráfico $\mathrm{n}^{\circ}$ 1: Carácter del elemento inicial

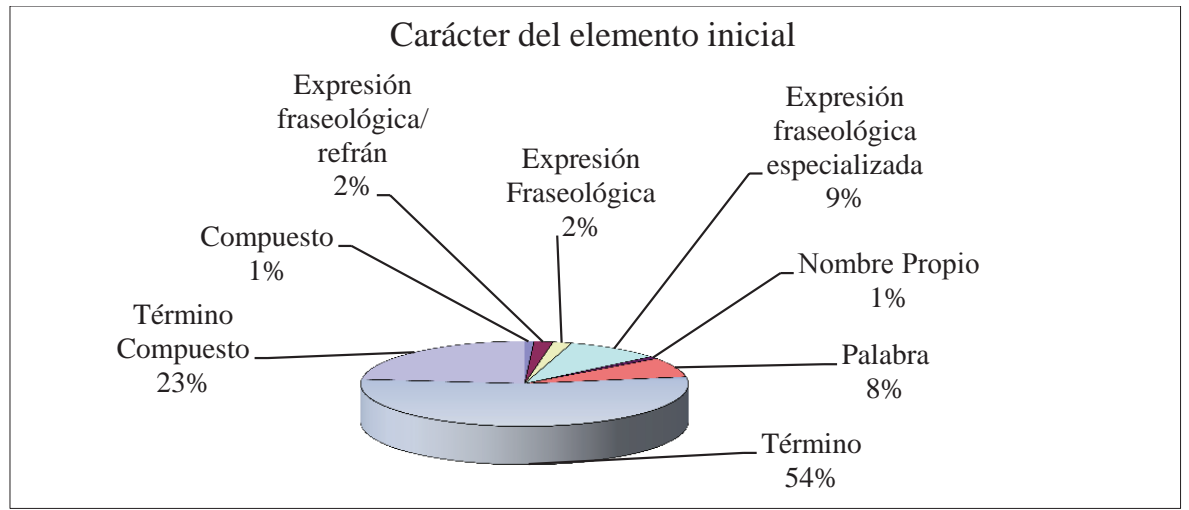

\subsection{Mecanismos lingüísticos}

Sobre los 107 elementos iniciales detectados actúan 382 mecanismos léxicos, que aparecen en 300 combinaciones asociadas a 33 patrones diferentes (Anexo). Su carácter eminentemente terminológico se puede observar por la baja aparición del préstamo esporádico, que supone un 17.5\%, y la abundancia de mecanismos perifrásticos, que suponen un 32.72\% del total. Esto nos lleva a deducir una falta de léxico en la lengua de llegada para expresar los conceptos y sentidos deseados. Al mismo tiempo, el uso de equivalentes y de préstamos incorporados y xenismos suponen un $24.12 \%$ y un $24.31 \%$, respectivamente. En el primer caso, nos encontramos 
usualmente ante términos de carácter vinícola general, demostrando, por tanto, que son más fácilmente trasladables de una lengua a otra, en este caso, de español a inglés. En el segundo, se recogen mayoritariamente aquellos usos específicos de cada zona vitivinícola, sin equivalentes en la lengua de llegada y que han sido exportados a esta. El calco reduce su porcentaje a un $6.02 \%$.

Gráfico nº 2: Mecanismos léxicos aislados

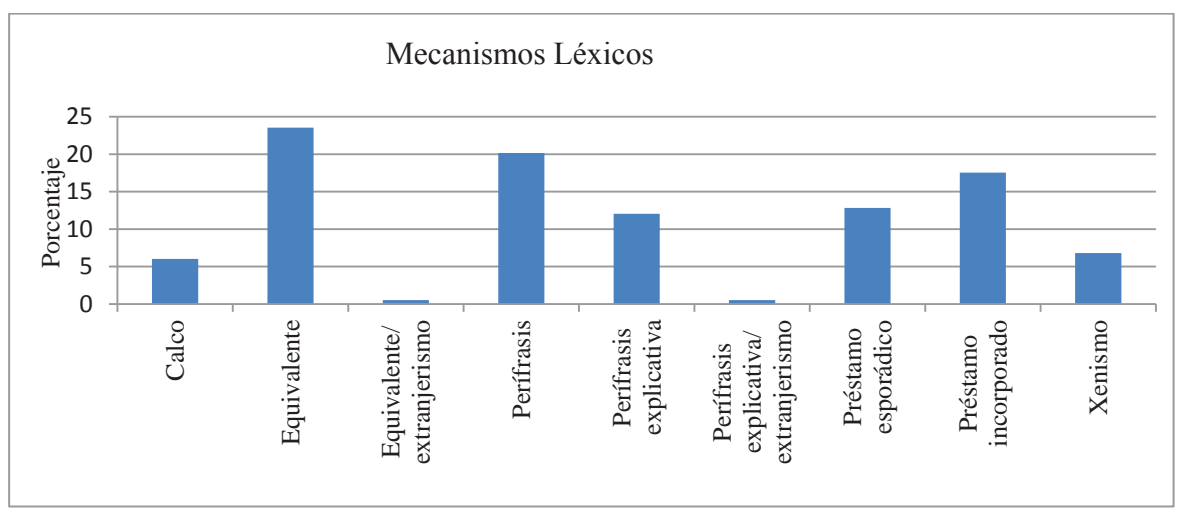

Aparecen también de forma recurrente muchas combinaciones léxicas en las que se subordinan o yuxtaponen dos, tres y hasta cuatro mecanismos lingüísticos diferentes, en los que destaca la incorporación en casi todos ellos de uno o varios procedimientos perifrásticos. La combinación más utilizada es la compuesta por un préstamo (habitualmente esporádico) más una o varias perífrasis explicativas. Es decir, el autor ha continuado con la técnica ya comentada, introduciendo el elemento inicial en español en la mayoría de los casos y clarificando su sentido a través de mecanismos léxicos diferentes Sin embargo, en muchas ocasiones los elementos iniciales responden a préstamos incorporados o a xenismos, como bodega, borracha, bota, Jerez, Málaga, manzanilla, Valdepeñas, etc., cuyas apariciones se repiten constantemente haciendo incrementar de manera notable el porcentaje de estos mecanismos.

La proliferación de la literatura de viajes en el s. XIX y, en concreto, la gran difusión de la obra de Richard Ford en Gran Bretaña, tuvo como consecuencia la incorporación de numerosos vocablos españoles al sistema de la lengua inglesa, siendo precisamente esta época en la que se produjo la incorporación de muchos préstamos a la misma. Los préstamos incorporados referentes al campo asociativo de la viña y el vino que aparecen en esta obra, cuya fijación a la lengua inglesa se ha constatado por su inclusión en el Compact Oxford English Dictionary ${ }^{4}$ (1994) son numerosos. A modo de ejemplo incluimos los siguientes:

- Bodega: “A wine-shop in Spain; recently adopted as a special name for a

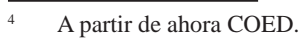


cellar or shop for the sales of wines only" (COED: 153). El diccionario aporta precisamente la cita perteneciente a Gathering from Spain "the best vineyards and bodegas or cellars are those which did belong to Don Carlos [...]” (162) para constatar la aparición de este vocablo en lengua inglesa por vez primera. Es necesario comentar la necesidad de incorporación de este término en inglés debido a que el concepto de bodega español, al igual que sucede en otros países, como Portugal, es más amplio que el británico, pues es aplicable tanto a las bodegas subterráneas como a las de superficie, entre las que se engloban las jerezanas, de peculiares características, de gran tamaño y altura, orientadas hacia el mar, realidad inexistente en Gran Bretaña. Por ello, la incorporación de este elemento completa una casilla léxica vacía en inglés, ya que su posible equivalente cellar no es aplicable en este contexto jerezano.

- Bota: La acepción que recoge el COED (161) es la siguiente: “(Sp) A small leather bottle for holding wine”, utilizado por vez primera en lengua inglesa en 1832. Nos encontramos, pues, ante la incorporación al sistema de la lengua de una palabra o léxico común, ya que su definición alude al receptáculo de cuero donde se guarda cualquier tipo de vino. Sin embargo, en el texto analizado aparece también el término jerezano homónimo 'bota', en referencia a la barrica de roble americano en la que se madura y conserva el vino de Jerez. En este segundo caso nos encontramos ante un término vitivinícola usado como préstamo esporádico.

- Capataz: Aunque el uso del xenismo ‘capataz’ se remonta a 1826, la acepción recogida es "In Spanish-speaking countries, a headman of a ranch or farm; a foreman or overseer of a group of labourers" (COED: 209), es decir, tan solo recoge la acepción agraria. Sin embargo, en la bodega, el capataz asume responsabilidades distintas, siendo uno de los máximos responsables de organizar y supervisar las tareas relativas al cuidado y clasificación del vino y el mantenimiento de las botas. Con este matiz de significado, el vocablo se utiliza como un término bodeguero y, por ende, como un préstamo esporádico en este contexto especializado.

- East Indian Sherry: Curiosamente East Indian Sherry es un término vinícola jerezano acuñado originalmente en inglés, al igual que pale sherry, otro tipo de vino generoso jerezano ${ }^{5}$. Su traducción al español es inexistente - por no usada - en este ámbito. La interferencia entre ambas lenguas es total, pues llega, como en este caso, a denominarse a dos tipos de vino de Jerez con vocablos ingleses por haber sido comercializados en su mayoría por familias de origen británico, como Garvey, Duff, Williams, Humbert, Byass Terry, Osborne, etc., y dirigidos a su consumo y preferencias, dando lugar a este tipo de paradojas.

Pale hace referencia aquí a su pálido color pajizo. En el ámbito bodeguero del Marco de Jerez y Montilla-Moriles se usa la expresión palo cortado para referirse a un tipo de vino con aroma de amontillado y paladar de oloroso, cuya evolución hacia ese estado se distingue entre las diferentes botas por una marca vertical (palo) y otra horizontal cruzada (de ahí cortado). No existe, pues, relación semántica entre pale y palo. 
- Sherry: "Originally, the still white wine made near Xerez [...] in modern use, extended to a class of Spanish fortified white wines of similar character and to wines made elsewhere in imitation of Spanish Sherry. Also, a wine of this kind” (COED: 1742). La constatación de su uso se remonta a 1603.

- Xerez: "Name of a town in Andalucia, famous for its wine. In full xerez sack, wine = Sherry" (COED: 2353). Hemos considerado Xerez como xenismo y no como préstamo pues su uso no se ha extendido para denominar vinos de procedencias distintas a esta denominación de origen, como sí ha ocurrido con Sherry.

- Malaga [sic]: “A white wine exported from Malaga [...]” (COED: 1024). Utilizado por vez primera con esta acepción en 1608.

- Manzanilla: "A kind of dry and light sherry with a somewhat bitter flavour" (COED: 1034). Utilizado por primera vez en lengua inglesa en 1843. También existe la acepción referente al tipo de oliva, pero no se incorpora hasta 1911.

- Amontillado: "Formerly, a wine of the sherry type produced in Montilla; now, a matured sherry in which the "flor" has developed. 2. Attrib. in fig. sense [...] “[...] I ask in my amontillado manner [...]” (COED: 46). Su uso en inglés se remonta a 1825. Es curioso el uso del préstamo 'flor' en la propia definición de 'amontillado'. La 'flor' (también llamada 'velo') es una fina capa de levadura que se produce en la superficie de los vinos e incluso de otros alimentos, debido a la fermentación de los mismos, siendo un componente esencial en el sistema de crianza jerezano: "Film of yeast cells which grows spontaneously during maturation on the surface of fermented musts, which will later be used for the making of certain types of Sherry especially 'Finos' and 'Àmontillados'. It protects the wine from contact with the air, in that way avoiding oxidation and preventing the wine from becoming vinegary" (Noya 1993: 227). Su existencia o pérdida deriva en un tipo de vino u otro.

- Fino: “A type of dry sherry. A glass of such sherry” (COED: 593). Una vez más, R. Ford y Gatherings from Spain son utilizados por el diccionario como autoridad para constatar el uso de este elemento en lengua inglesa por vez primera, a través de la siguiente cita: "those only which exhibit great delicacy, body, and flavour are called finos or fine" (168).

Todo lo anterior se ve reflejado en las relaciones semánticas implícitas en cada combinación de mecanismos léxicos. Así, de las 300 combinaciones analizadas, la mayoría existente de equivalentes y perífrasis se transmiten a través de procesos de generalización o hiperonimia, en 162 ocasiones. Por otra parte, el alto porcentaje de préstamos se refleja en el importante índice de no-proceso o proceso neutro, que se contabiliza en 134 casos, en los que aparecen elementos cohipónimos al inicial, o que coinciden con este. Tan solo aparecen cuatro casos de especialización del significado.

En cuanto a los mecanismos semánticos, destaca la elipsis, con 66 casos y la metáfora, con 33 apariciones. Este hecho se debe a la tendencia elíptica de esta 
terminología, donde los líquidos se suelen denominar sin la palabra vino, que se supone por añadidura. Las metáforas son también utilizadas de modo recurrente para definir la calidad de los caldos. Normalmente son las antropomórficas y las sinestésicas las que aparecen con más asiduidad. La metonimia es también otro procedimiento semántico importante, pues aparece en 50 ocasiones, debido a la tendencia en este ámbito a denominar al vino por el lugar donde se produce, principalmente.

\subsection{Análisis léxico}

El análisis realizado demuestra que Richard Ford concede, como la mayoría de los viajeros de la época, una importancia especial al vino de Jerez frente al resto de los vinos producidos en España, desde las tierras en las que se cultivan las viñas, sus tipos y características, su peculiar sistema de elaboración y envejecimiento, etc. Este hecho se debe a la importancia de las relaciones comerciales basadas en este producto, que lo configuraban como uno de los vinos extranjeros más conocidos y estimados en la Gran Bretaña del siglo XIX, junto al importante papel que la ciudad jugaba en las rutas de estos viajeros debido al establecimiento definitivo de familias de origen británico en Jerez ${ }^{6}$. Muestra de este hecho es que de los 107 elementos iniciales diferentes que conforman este campo asociativo, 54, es decir prácticamente la mitad, hacen referencia de una manera u otra a estos tipos de caldos jerezanos frente al resto de la producción vinícola española.

Destaca en primer lugar la reiteración del elemento inicial bota, en su acepción jerezana, es decir, aquella que hace referencia a las barricas de roble americano en las que se almacena el vino producido en la comarca del jerez para su posterior envejecimiento, no al objeto de cuero tan característico como parte de la indumentaria del español de la época. Este elemento aparece en 41 ocasiones, de las cuáles, tan solo una corresponde al préstamo, mientras que en 38 casos se recurre a un equivalente, generalmente hiperónimo, como cask, butt, o barrel, y en 2, a mecanismos perifrásticos. Este es un hecho a destacar si lo comparamos con la otra acepción existente en la obra de la palabra 'bota', es decir, aquella que alude al cuero, que aparece en 38 ocasiones; su uso, pues, también es notable. La diferencia estriba en que de estos 38 casos, 30 corresponden a la acepción que sí se recoge como préstamo incorporado, una muestra clara de que R. Ford está aludiendo a conceptos totalmente diferentes, que en un caso traslada a través de un préstamo conocido, mientras que en el otro, aun siendo homónimos, ha de utilizar diferentes equivalentes para hacer referencia a la realidad jerezana.

\footnotetext{
De las cuatro comunidades británicas más importantes existentes en la península (Gibraltar, Oporto, Jerez y Río Tinto), cuya razón de ser es o bien política o simplemente económica, tres de ellas se encuentran en Andalucía: Gibraltar, Jerez de la Frontera y Río Tinto. La importancia de Gibraltar es obvia, no solo porque ya a comienzos del siglo XIX era una colonia británica plenamente consolidada, sino también por su carácter estratégico, político y comercial. En cuanto a Jerez, su comarca fue objeto de un gran cambio durante el siglo XIX, en busca de nuevos mercados de exportación del vino, que comenzaron a ampliarse a partir de 1840, suponiendo una importante fuente de ingresos para el país. La zona de viñas aumentó en un 50\% entre 1817 y 1851, y otro 50\% en los veinte años siguientes. Las ganancias por exportación de vino y brandy llegaron a sumar en 1850 el 28\% de los ingresos totales en España (Ramos y Maldonado 1996). La comarca de Río Tinto, en la provincia de Huelva, es un claro exponente de que la inmensa riqueza minera española, que la convertía en uno de los centros mineros más importantes del momento, estaba controlada por intereses extranjeros, con la excepción de las minas de carbón asturianas. Debido una serie de leyes aprobadas en 1859 y 1869, cualquier inversor podía participar en este sector, con lo que el capital extranjero, en su mayoría británico, encontró óptimos horizontes para sus actividades (Cameron 1990: 306).
} 
El segundo elemento en orden de aparición es Jerez, en 36 ocasiones, 30 de ellas a través del préstamo incorporado 'Sherry', 2 mediante mecanismos perifrásticos y 3 a través del xenismo 'Xerez', posiblemente influenciado por la grafía antigua del topónimo ${ }^{7}$. Este hecho responde a la importancia que se concedía a este tipo de vino, que se ve incrementada por la incorporación de numerosos elementos relacionados directamente con su producción, como arrope al quinto, albariza, arrumbador, bajo, barras, cocer, Palomina Blanca, venencia, estar a rajavaso, entre muchos otros. Destacan aquellos más peculiares y característicos para el autor, como capataz, en 12 ocasiones, cabeceo, en 8, manzanilla, en 7, mosto, en 7 y término (con la acepción de 'marco del jerez'), en 6 . Sobresale, asimismo, el elemento inicial bodega, que aparece en 21 casos, 9 de ellos corresponden al xenismo que hace referencia a esa realidad inexistente en Gran Bretaña, 8 hacen alusión a este concepto a través de equivalentes, entre los que destaca cellar, aunque también se recogen los hiperónimos store o house, $\mathrm{y}$, finamente, también aparecen cuatro mecanismos perifrásticos, correspondientes a wine store, sherry wine vaults, o explicaciones del tipo "huge depositories all above ground, (...) the antithesis of our under-ground cellars” (170), en donde el propio autor hace referencia a esa falta de correspondencia entre realidades de diferentes países, o bien "cellars into which the must or pressed grape juice is left to pass the stages of fermentation”, (167) en donde esa casilla léxica vacía en la lengua de llegada hace necesarias este tipo de aclaraciones.

Por otro lado, las referencias al vino en general no solo se observan a través del uso común de bota, sino a las menciones a este mismo objeto u otros parecidos, a través de 'borracha', que aparece en 8 casos, y 'cuero', al que se hace referencia en 11. Aparecen también otros elementos iniciales que claramente aluden al vino de otras procedencias, como Valdepeñas, Vino de Toro, Vino de Niebla, Chacolí, Vino de Chipre, etc., o a elementos vinícolas generales como acre, agraz, anisado, avinagrar, estabilización, hollejo, porrón, verde, etc.

\section{CONCLUSIÓN}

Una vez llevado a cabo el análisis anterior, es decir, de cuantificación, clasificación y análisis semántico, estilístico y de frecuencia del campo asociativo vitivinícola en Gatherings from Spain, consideramos necesario contemplar todos los datos obtenidos, tanto de manera global como comparativa, pues los resultados muestran una clara confluencia de factores de interdependencia entre todos y cada uno de los parámetros analizados que llevan como consecuencia a su interpretación conjunta. Por ello, los resultados anteriores nos muestran su total interrelación, tanto con el carácter de los elementos iniciales que los conforman como con el tipo de mecanismos lingüísticos que aparecen en cada caso y sus relaciones semánticas. Se observa que las características terminológicas del campo asociativo inciden en el carácter de sus elementos iniciales, mayoritariamente términos, siendo este un rasgo definitorio con consecuencias directas en el tipo de mecanismo lingüístico empleado: el autor suele utilizar mayoritariamente el mecanismo lingüístico del equivalente hiperónimo en los casos en los que ha de trasladar al inglés términos vinícolas generales. Sin

Del árabe sherish y probablemente del fenicio xera (Anders 2001-2016). 
embargo, para referirse a aquellos conceptos específicos de un área geográfica determinada o de un tipo de elaboración concreta, sin equivalencia en la lengua de llegada, debe recurrir a estructuras más complejas en las que a menudo se yuxtaponen varios mecanismos lingüísticos y entre las que destaca la inclusión del préstamo cuyo significado se completa con perífrasis explicativas. El resultado muestra un compendio de interferencias tan amplio que corrobora que la interrelación entre ambos idiomas es tal que resulta casi imposible interpretar correctamente el sentido del texto si el lector no posee en su bagaje cultural el conocimiento de ambas esferas conceptuales a través de los dos idiomas implicados. Hemos observado este hecho en la esfera léxica de la viña y el vino, corroborando el aspecto antropológico y cultural que, como comentábamos al inicio, lleva implícita la producción y elaboración viti-vinícola. La ausencia del empleo de una terminología adecuada en estos casos muestra el desconocimiento por parte del autor de este tipo de léxico, evitando sus denominaciones exactas. Por otro lado, la abundancia de préstamos evidencia la importancia de esta esfera léxica en cuanto a la exportación de elementos que finalmente se han incorporado al sistema de la lengua inglesa como xenismos y que, como tales, aparecen en el COED. En cuanto a los mecanismos semánticos, el campo asociativo del vino, al igual que otros campos con un alto componente cultural, se presta ampliamente a los usos metafóricos, principalmente antropológicos, utilizados como denominaciones de los tipos de vino o sus características organolépticas. Es también notable el uso de la elipsis originada en combinatoria léxica para referirnos a sus variedades: un (vino) fino, un (vino) rioja, una (copa de) manzanilla, etc.

\section{OBRAS CITADAS}

Anders, Valentín (ed.). 2001-2016. Diccionario Etimológico. Recuperado de http://etimologias.dechile.net/ el 23 de mayo de 2016.

Alvar Ezquerra, Manuel. 1993. La formación de palabras en español. Madrid: Arco-libros.

Bajo Santiago, Francisca. 2001. "El léxico científico-técnico del vino en el DRAE". Las lenguas de especialidad y su didáctica. Eds. María Bargalló et al. Tarragona: Universitat Rovira i Virgili. 69-79.

Barros García, Pedro. 2008. "Estudio lingüístico sobre la terminología vitivinícola de tierra de Barros (Badajoz)”. Estudios de Lengua Española: Homenaje al profesor José María Chamorro. Eds. José M ${ }^{a}$ Becerra Horaldo y Francisco Torres Montes. Granada: Editorial Universidad de Granada. 51-70.

Cabré, Mª. Teresa. 1993. La Terminología. Teoría, Metodología, Aplicaciones. Barcelona: Antártida-Empúries.

Cabré, Ma . Teresa. 2007. "Términos y palabras en los diccionarios". Vernetzungen: Bedeutung in Wort, Satz und Text. Festschrift für Gerd Wotjak zum 65. Geburtstag. Eds. Juan Cuartero Otal y Martine Emsel. Frankfurt am Main: Peter Lang. 71-84.

Cameron, Rondo. 1990. Historia Económica Mundial. Desde el paleolítico hasta el presente. Madrid: Alianza Universidad Textos.

Carracedo Arroyo, Eleuterio. 2010. "El léxico de la viña y el vino en el sureste de la provincia de Soria”. Vino, lengua y Traducción. Ed. Miguel Ibáñez Rodríguez. Vol. 2, Valladolid: UVA. 197-216.

Deroy, Louis. 1980. L'emprunt linguistique. Paris: Belles Letres.

Dubois, Jean et al. 1992. Diccionario de Lingüística. Madrid: Alianza.

Feu Guijarro, Ma José, Ma Teresa de la Cuadra y Asunción Sánchez. 2003. “La relevancia del 
corpus oral en la confección de entradas léxicas de la cata de vinos: wine-tasting terms”. Resla 16: 53-66.

Ford, Richard. 1846. Gatherings from Spain. Londres: John Murray.

Gómez Capuz, Juan. 1998. El Préstamo Lingüístico. Conceptos, Problemas y Métodos. Valencia: Universidad de Valencia.

Gómez Capuz, Juan. 2000. Anglicismos léxicos en el español coloquial. Cádiz: UCA.

Gusmani, Roberto. 1981. Saggi sull'interferenza lingüística. Florencia: Le Lettere.

Guilbert, Louis. 1975. La creativité lexicale. Paris: Larousse.

Hatim, Basil e Ian Mason. 1995. Teoría de la Traducción. Una Aproximación al Discurso. Barcelona: Ariel.

Ibáñez Rodríguez, Miguel. 2007a. "La comunicación vitivinícola: vino, lengua y traducción". Le Bulletin de L'OIV - Revue Technique Internationale. Vol. 80 (911, 912, 913) 77-96.

Ibáñez Rodríguez, Miguel. 2007b. "Traducción y léxico vitivinícola a finales del siglo XVIII y comienzos del XIX”. Problemas lingüísticos en la traducción especializada. Coord. Pedro Fuertes Olivera. Valladolid: UVA. 67-86.

Ibáñez Rodríguez, Miguel. 2008. "El español de la vid y el vino. Aproximación dialectológica”. Homenaje al profesor César Hernández. Eds. Antonio Álvarez, Antonio Bueno et al. Valladolid: Diputación Provincial y UVA. 389-401.

Ibáñez Rodríguez, Miguel, ed. 2010a "El dominio vitivinícola: de la cepa a la copa". Vino, lengua y traducción. Valladolid: UVA. 227-258.

Ibáñez Rodríguez, Miguel. 2010b. 43 palabras de la vid y el vino. Logroño: Consejería de Agricultura, Ganadería y Desarrollo Rural. Gobierno de La Rioja.

Jeffs, Julian. 1994. El Vino de Jerez. Cádiz: Universidad de Cádiz.

Lázaro Carreter, Fernando. 1990. Diccionario de Términos Filológicos. Madrid: Gredos.

Lewandowski, Theodor. 1992. Diccionario de Lingüística. Madrid: Cátedra.

Martínez Ezquerro, Aurora. 2007. "Las palabras del vino. Un recorrido léxico por la vinificación riojana”. Belezos: Revista de cultura popular y tradiciones de La Rioja 4: 85-89.

Mighetto, David. 1993. "Palabras-cita en la prensa española 1977”. Actas do XIX Congreso Internacional de Lingüística e Filoloxía Románicas, vol. II: Lexicología e metalexicología. Ed. Ramón Lorenzo. A Coruña: Fundación “Conde de Fenosa”. 563-584.

Moliner, María. 1992. Diccionario del Uso del Español. Madrid: Gredos.

Montañés, Enrique. 2000. "El Vino de Jerez en el sector exterior español 1838-185". Revista de Historia Industrial 17: 189-209.

Murray, James et al., eds. 1994. The Compact Oxford English Dictionary. Oxford: O.U.P.

Noya Gallardo, Carmen. 1993. La Terminología Vinícola Jerezana en Inglés. Cádiz: UCA.

Onions, Charles T. et al., eds. 1994. The Oxford Dictionary of English Etymology. Oxford: O.U.P.

Paredes, Ma Jesús. 2010. "El lenguaje de la cata técnica de los vinos de Jerez". Vino, lengua y traducción. Ed. Miguel Ibáñez Rodríguez. Valladolid: UVA. 137-146.

Payrató, Lluís. 1984. "Barbarismes, manlleus I interferències. Sobre la terminología dels contactes interlingüístics”. Els Marges 32: 45-58.

Quilis, Antonio. 1996. Lengua Española III. Madrid: U.N.E.D.

Ramos, Alberto y Joaquín Maldonado, eds. 1996. El jerez-xérès-sherry en los tres últimos siglos. El Puerto de Sta. Ma: UCA y Ayuntamiento de El Puerto de Sta. Ma.

Richards, Jack C., John Platt y Heidi Platt. 1993. Longman Dictionary of Language Teaching and Applied Linguistics. Singapore: Longman.

Seco, Manuel, Olimpia Andrés y Gabino Ramos. 1999. Diccionario del español actual. Madrid: Aguilar.

Smith, Linda y Miguel Casas. 1982. Cambios semánticos en el léxico vitivinícola de Jerez. Sevilla: USE.

Trujillo, Ramón. 1997. “El Papel de la realidad en la semántica”. Jornadas de Lingüística. Dir. 
Miguel Casas. Ed. Jacinto Espinosa. Cádiz: UCA. 31-53.

Ullmann, Stephen. 1983. Semantics. An Introduction to the Science of Meaning. Oxford: Basil Blackwell.

Wislocka Breit, Bocena. 2012. Aplicación de la teoría de la valoración a las fichas de cata de vino en inglés, español y polaco y sus respectivas traducciones desde una perspectiva intercultural. Tesis doctoral. UNED.

Wislocka Breit, Bocena. 2014. "Appraisal Theory applied to the wine tasting sheet in English and Spanish". Ibérica 27: 97-120.

Zuluaga, Alberto. 2001. "Análisis y traducción de unidades fraseológicas desautomatizadas". Philologie im Netz 16/2001, 67-83.

1. Anexo

Tabla n ${ }^{\circ}$ 1: Mecanismos Léxicos Aislados

\begin{tabular}{|l|c|c|}
\hline \multicolumn{1}{|c|}{ Mecanismo Léxico Aislado } & Porcentaje & Número \\
\hline$-\quad$ Calco & $6.021 \%$ & 23 \\
\hline$-\quad$ Equivalente & $23.56 \%$ & 90 \\
\hline$-\quad$ Equivalente/Extranjerismo & $0.524 \%$ & 2 \\
\hline$-\quad$ Perífrasis & $20.16 \%$ & 77 \\
\hline$-\quad$ Perífrasis Explicativa & $12.04 \%$ & 46 \\
\hline$-\quad$ Perífrasis Explicativa/Extranjerismo & $0.524 \%$ & 2 \\
\hline$-\quad$ Préstamo Esporádico & $12.83 \%$ & 49 \\
\hline$-\quad$ Préstamo Incorporado & $17.54 \%$ & 67 \\
\hline$-\quad$ Xenismo & $6.806 \%$ & 26 \\
\hline$-\quad$ TOTAL & $100 \%$ & 382 \\
\hline
\end{tabular}

Tabla $^{\circ}$ 2: Combinaciones de mecanismos léxicos

\begin{tabular}{|l|c|c|}
\hline Combinaciones de Mecanismos Léxicos & Porcentaje & Número \\
\hline$-\quad$ Calco & $5.33 \%$ & 16 \\
\hline$-\quad$ Calco + Equivalente & $0.67 \%$ & 2 \\
\hline$-\quad$ Calco + Perífrasis + Préstamo Incorporado & $0.33 \%$ & 1 \\
\hline$-\quad \begin{array}{l}\text { Calco + Perífrasis Explicativa(2) + Préstamo } \\
\quad \text { Esporádico }\end{array}$ & $0.67 \%$ & 2 \\
\hline$-\quad \begin{array}{l}\text { Calco + Perífrasis Explicativa + Préstamo Es- } \\
\text { porádico }\end{array}$ & $0.33 \%$ & 1 \\
\hline$-\quad$ Calco + Préstamo Esporádico & $0.67 \%$ & 2 \\
\hline$-\quad$ Equivalente & $26 \%$ & 78 \\
\hline$-\quad$ Equivalente + Perífrasis & $1 \%$ & 3 \\
\hline
\end{tabular}




\begin{tabular}{|c|c|c|c|}
\hline- & $\begin{array}{l}\text { Equivalente + Perífrasis Explicativa (2) + Pe- } \\
\text { rífrasis Explicativa/ Extranjerismo + Préstamo } \\
\text { Esporádico }\end{array}$ & $0.33 \%$ & 1 \\
\hline- & $\begin{array}{l}\text { Equivalente + Perífrasis Explicativa + Préstamo } \\
\text { Esporádico }\end{array}$ & $0.33 \%$ & 1 \\
\hline- & Equivalente + Préstamo Esporádico & $1 \%$ & 3 \\
\hline- & Equivalente + Préstamo Incorporado & $0.33 \%$ & 1 \\
\hline- & Equivalente + Xenismo & $0.33 \%$ & 1 \\
\hline- & $\begin{array}{l}\text { Equivalente/Extranjerismo (2) + Préstamo Es- } \\
\text { porádico }\end{array}$ & $0.33 \%$ & 1 \\
\hline- & Perífrasis & $15 \%$ & 45 \\
\hline- & Perífrasis (2) + Préstamo Esporádico & $0.33 \%$ & 1 \\
\hline- & $\begin{array}{l}\text { Perífrasis + Perífrasis Explicativa (2) + Présta- } \\
\text { mo Esporádico }\end{array}$ & $0.67 \%$ & 2 \\
\hline- & $\begin{array}{l}\text { Perífrasis + Perífrasis Explicativa + Perífrasis } \\
\text { Explicativa/Extranjerismo + Préstamo Esporá- } \\
\text { dico }\end{array}$ & $0.33 \%$ & 1 \\
\hline- & $\begin{array}{l}\text { Perífrasis + Perífrasis Explicativa + Préstamo } \\
\text { Esporádico }\end{array}$ & $0.67 \%$ & 2 \\
\hline- & $\begin{array}{l}\text { Perífrasis + Perífrasis Explicativa + Préstamo } \\
\text { Incorporado }\end{array}$ & $0.33 \%$ & 1 \\
\hline- & Perífrasis + Perífrasis Explicativa + Xenismo & $0.33 \%$ & 1 \\
\hline- & Perífrasis + Préstamo Esporádico & $5.33 \%$ & 16 \\
\hline- & Perífrasis + Préstamo Incorporado & $0.67 \%$ & 2 \\
\hline- & Perífrasis + Xenismo & $0.33 \%$ & 1 \\
\hline- & Perífrasis Explicativa & $4.33 \%$ & 13 \\
\hline- & $\begin{array}{l}\text { Perífrasis Explicativa (2) + Préstamo Esporádi- } \\
\text { co }\end{array}$ & $0.33 \%$ & 1 \\
\hline- & $\begin{array}{l}\text { Perífrasis Explicativa (3) + Préstamo Incorpo- } \\
\text { rado }\end{array}$ & $0.33 \%$ & 1 \\
\hline- & Perífrasis Explicativa + Préstamo Esporádico & $2 \%$ & 6 \\
\hline- & Perífrasis Explicativa + Préstamo Incorporado & $0.33 \%$ & 1 \\
\hline- & Perífrasis Explicativa + Xenismo & $1.33 \%$ & 4 \\
\hline- & Préstamo Esporádico & $3.33 \%$ & 10 \\
\hline- & Préstamo Incorporado & $20 \%$ & 60 \\
\hline- & Xenismo & $6.33 \%$ & 19 \\
\hline- & TOTAL & $100 \%$ & 300 \\
\hline
\end{tabular}

